\title{
Transtubular Anterior Cervical Foraminotomy for the Treatment of Compressive Cervical Radiculopathy: Surgical Results and Complications in a Consecutive Series of Cases
}

\author{
Rodolfo Maduri ${ }^{1}$, Giulia Cossu ${ }^{2}$, Viviana Aureli ${ }^{2}$, Sonia Plaza Wüthrich ${ }^{3}$, \\ Lukas Bobinski ${ }^{4}$, John Michael Duff ${ }^{1}$ \\ ${ }^{1}$ Avaton Surgical Group, Clinique de Genolier, Swiss Medical Network, Genolier, Switzerland \\ ${ }^{2}$ Department of Clinical Neurosciences, Service of Neurosurgery, Centre Hospitalier Universitaire Vaudois, Lausanne, Switzerland \\ ${ }^{3}$ Centre Leenaards de la Memoire, Centre Hospitalier Universitaire Vaudois, Lausanne, Switzerland \\ ${ }^{4}$ Spine Unit, Department of Orthopedics, University Hospital of Umeå, Umeå, Sweden
}

\begin{abstract}
Study Design: This was a retrospective review of patients with compressive cervical radiculopathy treated with a minimally invasive anterior cervical foraminotomy (ACF).

Purpose: This study aimed to evaluate the results and complication rates of ACF in a consecutive series of patients and to report our clinical results of ACF as a minimally invasive technique in a series of 45 consecutive patients treated for compressive cervical radiculopathy.

Overview of Literature: ACF is a motion-sparing procedure and an alternative to anterior cervical discectomy and fusion (ACDF) and posterior cervical foraminotomy for direct nerve root decompression in patients with compressive cervical radiculopathy.

Methods: The chart review recorded clinical and radiological features preoperatively and postoperatively and at follow-up (FU). The effect of prognostic factors was analyzed in relation to the clinical outcome.

Results: Between January 2004 and October 2019, 45 patients (15 females and 30 males) with a mean age of 55.9 years (range, 28-78 years) underwent ACF for unilateral cervical radiculopathy. The global clinical outcome according to the MacNab scale was evaluated as excellent in $64.5 \%$ of patients $(n=29)$, good in $28.9 \%(n=13)$, fair in $4.4 \%(n=2)$, and poor in $2.2 \%(n=1)$. The radiological FU was available for $73.3 \%$ ( $n=33)$. The statistical analysis revealed no influence of age, sex, operated level, and side on the clinical outcome. Only one patient (2.2\%) exhibited spontaneous bone fusion at the operated level on FU after a right-sided C6-7 ACF with no clinical consequences. No patient presented with signs of delayed segmental instability. The overall reoperation rate of this series was $4.4 \%$.

Conclusions: ACF is a feasible and low-cost alternative to ACDF in selected patients with cervical radiculopathy. The use of tubular retractors in ACF may confer an added advantage that creates a safe corridor for direct cervical root decompression yet minimizing surrounding soft tissue retraction and avoiding unnecessary bone removal.
\end{abstract}

Keywords: Diskectomy; Radiculopathy; Herniated discs; Spondylosis; Cervical vertebrae

Received Jun 25, 2020; Revised Jul 8, 2020; Accepted Jul 12, 2020

Corresponding author: Rodolfo Maduri

Neurosurgery, Clinique de Genolier, Swiss Medical Network, Route de Muids 3, CH 1272 Genolier, Switzerland

Tel: +41-22-366-9771, Fax: +41-22-366-9196, E-mail: rmaduri@genolier.net 


\section{Introduction}

Cervical radiculopathy may result from cervical disk herniation ("soft" disk) and/or osteophyte formation ("hard" disk) causing nerve root compression. Anterior cervical discectomy and fusion (ACDF), which enables direct decompression and indirect nerve root decompression through augmentation of the foraminal height [1], is the most common surgical procedure for degenerative cervical radiculopathy worldwide. Despite the favorable clinical outcomes of ACDF, a major drawback of this procedure is loss of motion at the index level, which may cause adjacent segment degeneration, secondary radiculopathy or myelopathy, and pseudarthrosis [2].

Artificial disk replacement (ADR) was developed as a motion-preserving procedure to reduce or eliminate the risk of adjacent segment disease. However, in terms of clinical outcome, the superiority of ADR over ACDF has not yet been clearly proven and implants remain expensive [3].

Foraminotomy, either from anterior or posterior, is an alternative surgical procedure for direct nerve root decompression in cervical radiculopathy [4-6]. It has been reported that anterior cervical foraminotomy (ACF) is a safe and feasible "functional surgery" for direct nerve root decompression with preservation of the motion segment $[4,5]$. Furthermore, ACF does not require stabilization, which allows the surgeon to circumvent fusion-related complications including pseudarthrosis and to lower the costs [7]. Since the first description from Jho [4] in 1996, this technique remained controversial and has not been widely adopted by surgeons as a valid alternative to ACDF despite the satisfactory results in terms of safety and feasibility of ACF as treatment for cervical radiculopathy [5,8-15]. A major concern limiting the acceptance of ACF is the risk of vertebral artery (VA) injury $[8,12]$. Some authors also raised that ACF could lead to segmental instability, with the need for further surgery for fusion $[6,16]$.

We have recently described a variant of the "minimally invasive" technique for ACF using tubular retractors for transuncal decompression of compressive cervical radiculopathy [17]. The use of tubular retractors not only facilitates soft tissue retraction but also helps to ensure the appropriate surgical trajectory for bone resection leading directly to the neural foramen. This may aid to avoid complications and may lower the reoperation rate. In this study, we described our recent results using a minimally invasive ACF in a series of 45 consecutive patients with compressive cervical radiculopathy.

This study aimed to report the clinical outcome of our series of patients operated with ACF for cervical radiculopathy and to compare the rate of surgical complications and reoperation with those reported in the literature.

\section{Materials and Methods}

\section{Patient population}

A retrospective review of medical records of patients surgically treated for degenerative spine disorders through an anterior approach in two institutions (Lausanne University Hospital and Genolier Clinic, Switzerland) was conducted from January 2004 to October 2019. The lead surgeon was the same in all cases (J.M.D.).

The inclusion criteria were as follows: (1) age of $>18$ years; (2) single- or two-level compressive cervical radiculopathy with predominantly foraminal pathology, refractory to conservative medical management for at least 2 months with or without signs of motor weakness; (3) preoperative cervical magnetic resonance imaging with T1W and T2W sagittal and coronal images confirming cervical soft disk herniation or cervical spondylotic spurs correlated with the clinical findings and computed tomography (CT) scan obtained selectively to verify bone detail [12]; and (4) surgical procedure conducted through an anterolateral approach with minimally invasive tubular ACF. Medical management comprised simple analgesics (paracetamol, nonsteroidal antiinflammatory drugs, and opioids) and physical therapy. Patients with cervical myelopathy, ossification of the posterior longitudinal ligament, subaxial kyphotic deformity, or cervical central canal stenosis and patients with signs of infection were excluded.

\section{Surgical technique}

The surgical technique used in this cohort of patients is similar to that described by Jho [4] and Saringer et al. [12] with the additional usage of tubular retractor [17]. The key steps of our surgical technique were summarized as follows: Through a $2 \mathrm{~cm}$ skin incision centered over the anterior border of the sternocleidomastoid muscle, the skin flaps were undermined and the platysma was opened along the lines of its fibers. The anterior aspect of the subaxial 


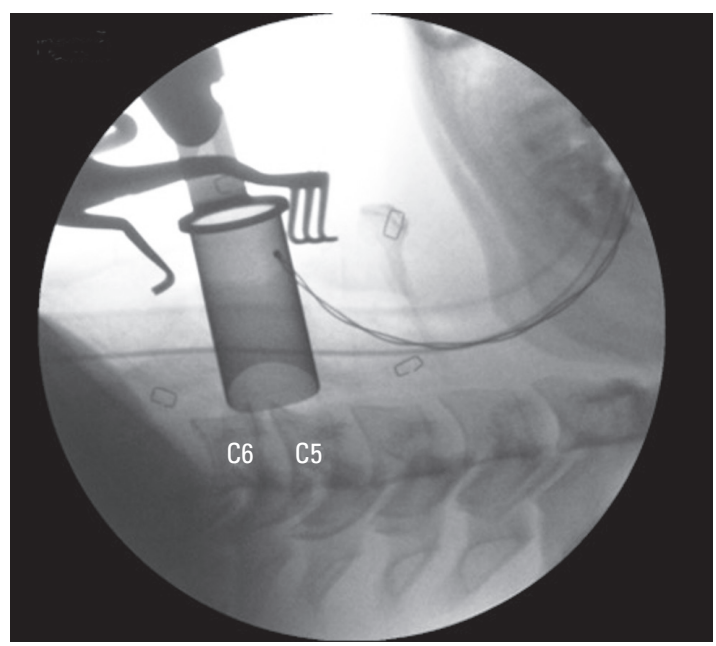

Fig. 1. Intraoperative lateral radioscopic image. The correct placement of the retractor system is verified correspondent of the index disk space (C5-C6).

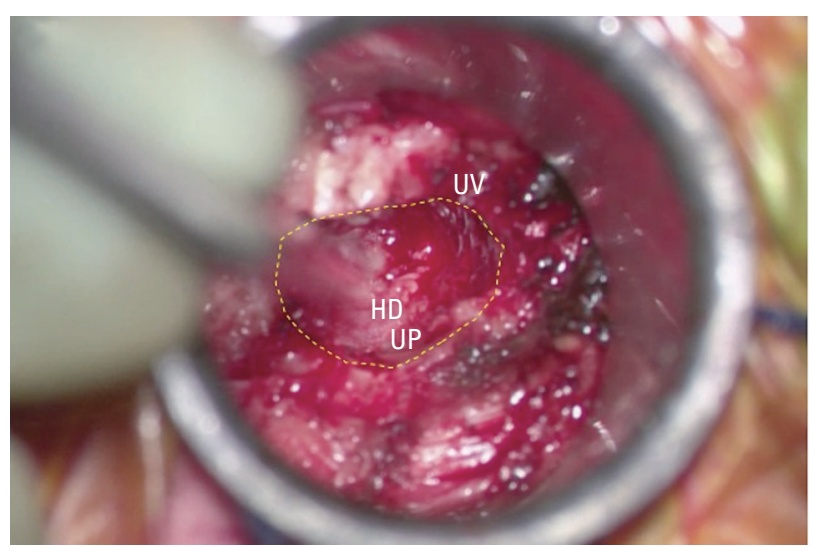

Fig. 2. Intraoperative picture. After drilling of the superior aspect of the C5 vertebral body and removal of the posterior half of the correspondent UP. The yellow dot line delimitates the anterior foraminotomy. UV, upper vertebral body; UP, uncinate process; HD, herniated disk.

cervical spine was exposed in the standard manner, albeit centered more laterally than with the standard skin incision. Under an operating microscope, the double layer of the prevertebral fascia was opened in line with the medial border of the longus colli muscle, centered on the index level. The prevertebral fascia was then mobilized laterally, taking the sympathetic chain with it. A thumbnail-sized portion of the longus colli muscle was resected to expose the uncovertebral joint from the base of one transverse process (TP) to the base of the TP below. An appropriately sized tubular retractor was placed, centered over the uncovertebral joint parallel to the index disk space (Fig. 1).

Bone resection was achieved by drilling on either side of the fibrous uncovertebral joint to achieve a superior

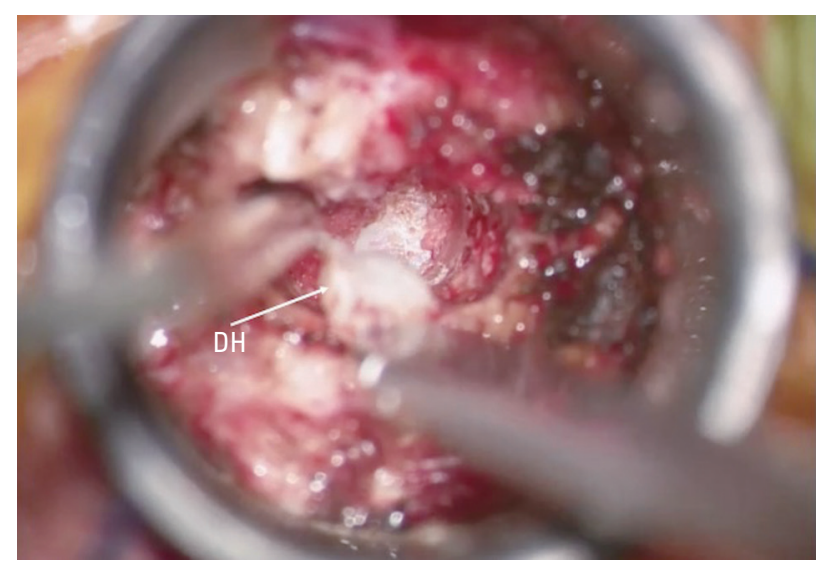

Fig. 3. Intraoperative image showing the removal of the DH through the anterior foraminotomy. DH, disk herniation.

vertebral transcorporeal approach (Fig. 2). The posterior longitudinal ligament was opened with a microsurgical hook and a $1 \mathrm{~mm}$ Kerrison to facilitate removal of herniated disk fragments (Fig. 3).

\section{Clinical evaluation}

The index level and acute intraoperative and postoperative complications (Horner's syndrome, nerve root injury, VA injury, or hemorrhage) were recorded. Patients were followed up at 6 weeks to 3 months, at 6 months, and at 1 year postoperatively. The following details at last followup (FU) were recorded: (1) presence of arm pain, (2) presence of neck pain, (3) return to work, (4) reoperation rate at the index and adjacent levels, and (5) global clinical outcome at the last FU using the MacNab scale [18].

The MacNab scale evaluates the clinical outcome as follows: (1) excellent (no pain; no restriction of activity), (2) good (occasional back or arm pain of sufficient severity that interferes with the patient's ability to do his normal work or his capacity to enjoy himself in his leisure hours), (3) fair (improved functional capacity but handicapped by intermittent pain of sufficient severity that curtails or modifies work or leisure activities), and (4) poor (no improvement or insufficient improvement to enable increase in activities; further operative intervention required).

\section{Radiological evaluation}

Two of the authors (V.A. and G.C.) reviewed the standing and dynamic (flexion-extension) radiographs of the cervical spine at each FU visit. CT scans were also evalu- 
ated when available. The radiological criteria used for segmental instability at the index level were the presence of relative sagittal plain translation at $>3.5 \mathrm{~mm}$ and/or sagittal plane rotation at $>11^{\circ}$ [19]. Radiological evidence of spontaneous bone fusion was also sought after.

\section{Statistical analysis}

The effect of several prognostic factors (age, sex, operated level, and side) was analyzed in relation to the clinical outcome using the $\chi^{2}$ test for categorical variables. In terms of age, the Kruskal-Wallis or Mann-Whitney U-test was used for two or >two groups, respectively (STATA ver. 15; Stata Corp., College Station, TX, USA). A $p<0.05$ was considered statistically significant.

\section{Results}

Over a period of 15 years, 45 patients (15 females and 30 males) underwent ACF for unilateral cervical radiculopathy, with a mean age of 55.9 years (range, 28-78 years) (Table 1). The mean FU period of 19.3 months (range, 6-120 months) and $68.8 \%(n=31)$ had at least 1 year of FU.

The most frequent operated level was C6-7 (67.3\%, 31 patients), with C4-5 and C5-6 at $15.2 \%(n=7)$ and $17.5 \%$ $(n=8)$, respectively (Table 1$)$. One patient was operated at two adjacent contiguous levels (C4-5 and C5-6) on the right side. Surgical results are summarized in Table 2.

The mean operative time was 103.7 minutes (range, 65-160 minutes). The mean blood loss was $63.8 \mathrm{~mL}$ (range, 20-250 mL). In terms of acute postoperative complica-

Table 1. Patients population

\begin{tabular}{lc} 
Characteristic & Value \\
No. of patients & 45 \\
\hline Male & 30 \\
\hline Female & 15 \\
\hline Age (yr) & $55.9(28-78)$ \\
\hline Level of pathology & $7(15.2)$ \\
\hline C4-C5 & $8(17.5)$ \\
\hline C5-C6 & $31(67.3)$ \\
\hline C6-C7 & $18.7(1-120)$ \\
\hline Follow-up period (mo) & \\
\hline
\end{tabular}

Values are presented as number, mean (range), or number (\%). tions, $4.4 \%$ of patients $(n=2)$ presented with transient Horner's syndrome. No other acute complications (nerve root injury, VA injury, hemorrhage, or wound infection) occurred.

At the final clinical evaluation, $88.8 \%$ of eligible patients returned to their previous working activity. There was a statistically significant difference between patients who returned to their previous work and the operated level $(p=0.028)$. There was a lower rate of patients returning to work if operated at the higher cervical levels (C4-5 and C5-6). This may be because the patients operated at high cervical levels (C4-5 and C5-6) had a median age higher than those operated at C6-7 (59.6 versus 54.6 years), even

Table 2. Surgical results after anterior cervical foraminotomy

\begin{tabular}{|c|c|}
\hline Variable & Value \\
\hline Arm pain relief & $36(80)$ \\
\hline Neurological complications & $2(4.4)$ \\
\hline Other complications & None \\
\hline Neck pain & $5(11.1)$ \\
\hline Surgical time (min) & $103.7(65-160)$ \\
\hline Blood loss (mL) & $63.8(20-250)$ \\
\hline Reoperation total & $2(4.4)$ \\
\hline Reoperation at the index level & $1(2.2)$ \\
\hline Reoperation at the adjacent level & $1(2.2)$ \\
\hline Return to work & $39(88.8)$ \\
\hline
\end{tabular}

Values are presented as number (\%) or mean (range).

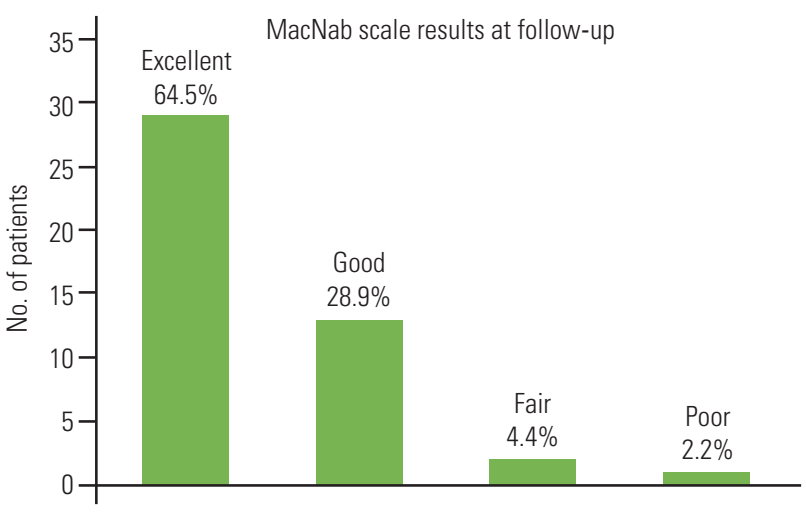

Fig. 4. Two-dimensional chart graphic showing the clinical results at follow-up according to the MacNab scale. MacNab scale grading: "excellent" (no pain, no restriction of activity), "good" (occasional back or leg pain of sufficient severity to interfere with the patient's ability to do his normal work or his capacity to enjoy himself in his leisure hours), "fair" (improved functional capacity but handicapped by intermittent pain of sufficient severity to curtail or modify work or leisure activities), and "poor" (no improvement or insufficient improvement to enable increase in activities; further operative intervention required). 
if no statistically significant difference is found $(p=0.08)$. Nonmechanical, nondisabling neck pain was reported by $11.1 \%$ of patients at $\mathrm{FU}(\mathrm{n}=5)$.

According to the MacNab scale, the global clinical outcome was evaluated as excellent in $64.5 \%$ of patients $(\mathrm{n}=29)$, good in $28.9 \%(\mathrm{n}=13)$, fair in $4.4 \%(\mathrm{n}=2)$, and poor in $2.2 \%(\mathrm{n}=1)$ (Fig. 4). Of the two patients with fair MacNab outcome, one patient had mild persistent neuropathic radicular pain after a right-sided C6-7 ACF. The second patient with fair MacNab outcome was previously operated with a two-level ACDF procedure (C5-6 and C6-7) in another institution and had persistent neck pain at FU after a subsequent $\mathrm{C} 4-5 \mathrm{ACF}$ in our institution. The only patient with poor MacNab outcome had persisting debilitating neuropathic radicular pain after a right-sided C6-7 ACF.

Statistical analysis revealed no influence of age, sex, operated level, and side with clinical outcome as measured by the MacNab scale ( $p>0.05)$. Radiological FU was available for $73.3 \%(n=33)$. Only one patient (patient 21) exhibited spontaneous bone fusion at the operated level after a right-sided C6-7 ACF (Fig. 5) with no clinical consequences. No patient exhibited any radiological evidence of instability.

Overall, two patients required reoperation for over 15 years (4.4\%). Patient 19 was operated with a right-sided C4-5 ACF and presented recurrent disk herniation and was reoperated 9 years later with an ACDF at the index level. The second patient (patient 4) was operated previously with a right-sided C5-6 ACF and developed adjacent-level disease requiring a C6-7 ACDF after 8 years (Fig. 6).

\section{Discussion}

ACF can be considered as a viable surgical alternative to $\mathrm{ACDF}, \mathrm{ADR}$, and posterior cervical foraminotomy (PCF) with no consensus on the optimal approach for cervical radiculopathy. Despite clear economic advantages in favor of ACF and PCF, the frequency of ACDF procedures is increased compared with foraminotomy [20].

This study aimed to investigate the clinical and radiological results after ACF with the use of tubular retractors to further prove the safety and effectiveness of this procedure. In our series, ACF has led to a good clinical result in a vast majority of patients with a low complications rate, thus confirming the findings of a previous ACF series (Table 3) $[5,8,11-13,15,16,21,22]$. We believe that the low

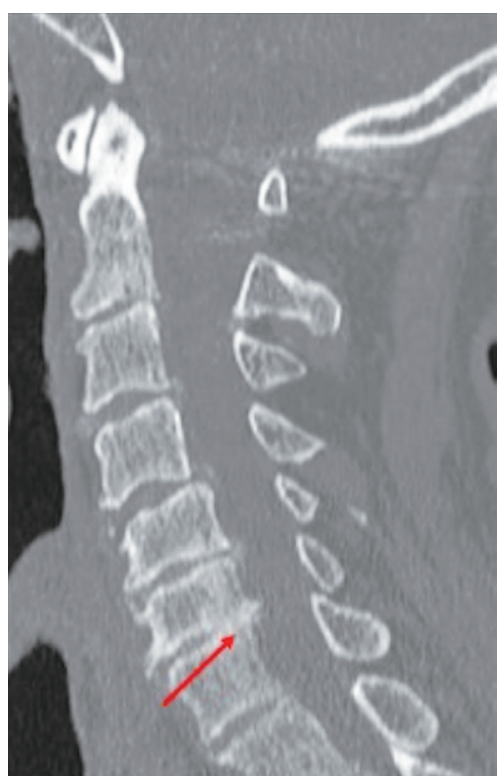

Fig. 5. Sagittal computed tomography scan at 10-year follow-up of patient 21. Bone fusion is present at the operated level after a right C6-C7 anterior cervical foraminotomy (red arrow) with no clinical consequences.
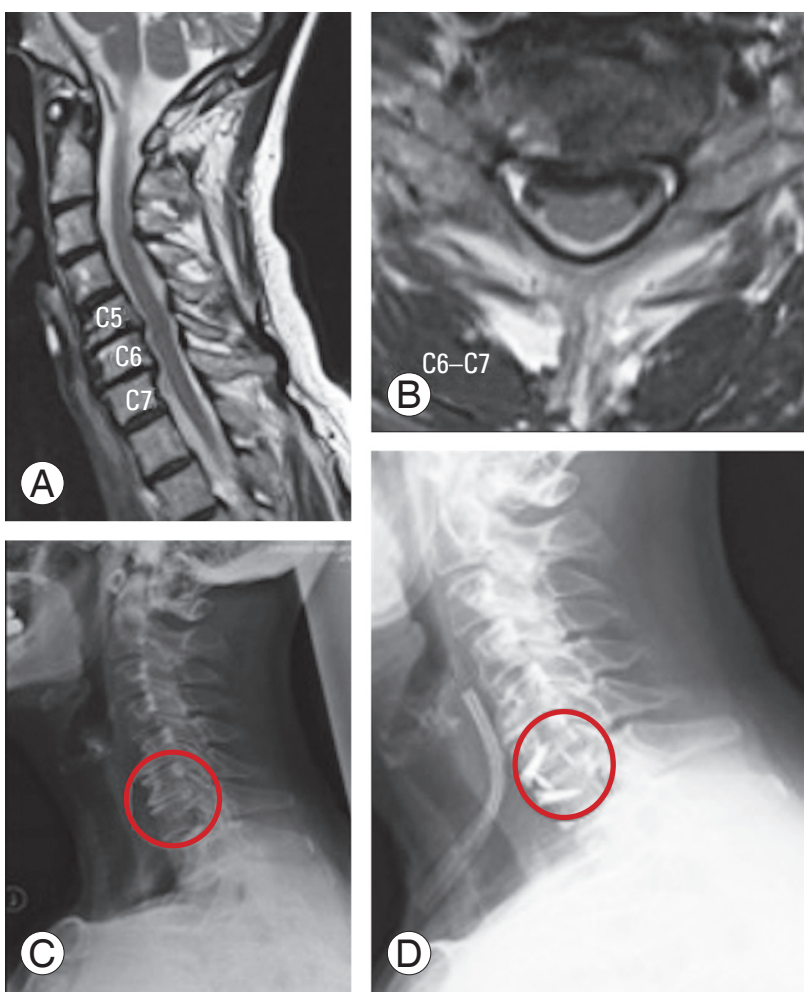

Fig. 6. Radiographic images of patient 4 with adjacent level disease at 8-year follow-up. ACDF was performed at C6-C7 level after a C5-C6 right anterior cervical foraminotomy. (A, B) Sagittal and axial magnetic resonance imaging at the time of the second surgery for $\mathrm{C} 6-\mathrm{C} 7$ adjacent level disease showing a C6-C7 disk herniation. (C) Preoperative standing X-rays of the cervical spine. (D) Standing X-rays of the cervical spine showing the C6-C7 space (red circle) before and after the ACDF procedure. ACDF, anterior cervical discectomy and fusion. 
Table 3. Anterior cervical foraminotomy series reported in literature

\begin{tabular}{|c|c|c|c|c|c|c|c|}
\hline \multirow{2}{*}{ Series (year) } & \multirow{2}{*}{$\begin{array}{c}\text { No. of } \\
\text { patients }\end{array}$} & \multirow{2}{*}{$\begin{array}{l}\text { Length of } \\
\mathrm{FU}(\mathrm{mo})\end{array}$} & \multirow{2}{*}{$\begin{array}{l}\text { Neurological } \\
\text { complication }\end{array}$} & \multirow{2}{*}{$\begin{array}{c}\text { Other } \\
\text { complications }^{\text {a) }}\end{array}$} & \multirow{2}{*}{$\begin{array}{l}\text { Overall good } \\
\text { clinical outcome } \\
\text { (at FU \%) }\end{array}$} & \multicolumn{2}{|c|}{ Reoperation rate } \\
\hline & & & & & & At the index level & At the adjacent level \\
\hline Johnson et al. [15] (2000) & 21 & 36 & $4.7(1 / 21)$ & NA & 85 & $9.5(2 / 21)$ & $4.7(1 / 21)$ \\
\hline Jho [5] (2002) & 104 & 74 & $4.0(3 / 74)$ & $1.3(1 / 74)$ & 99 & $1.3(1 / 74)$ & $2.7(2 / 74)$ \\
\hline Saringer et al. [12] (2002) & 34 & 17 & $8.8(3 / 34)$ & NA & 97 & $2.9(1 / 34)$ & NA \\
\hline Hacker and Miller [16] (2003) & 23 & 24 & NA & $4.3(1 / 23)$ & 52.1 & $6(6 / 23)$ & $4.3(1 / 23)$ \\
\hline Koc et al. [13] (2004) & 19 & 36 & $5.2(1 / 19)$ & NA & 89.4 & $5.2(1 / 19)$ & NA \\
\hline Lee et al. [11] (2006) & 13 & 25 & NA & NA & 84.6 & NA & NA \\
\hline Choi et al. [22] (2007) & 20 & 12 & $1(2 / 20)$ & NA & 92.8 & NA & NA \\
\hline Umebayashi et al. [21] (2013) & 35 & 84 & NA & NA & 94.2 & $8.5(3 / 35)$ & $2.9(1 / 35)$ \\
\hline Park et al. [8] (2013) & 44 & 84 & $15(7 / 44)$ & NA & 94 & NA & $4.5(2 / 44)$ \\
\hline Kim et al. [6] (2019) & 40 & 49.5 & NA & NA & NA & NA & NA \\
\hline Maduri et al. (2020, present study) & 43 & 120 & $4.7(2 / 43)$ & NA & 93.4 & $2.3(1 / 43)$ & $2.3(1 / 43)$ \\
\hline
\end{tabular}

Values are presented as number or \% (number/total number), unless otherwise stated.

FU, follow-up; NA, not available.

${ }^{\text {al }}$ Cervical hematoma, infection, long-term neck pain, and general medical complications (pulmonary embolism, cerebral infarction).

complication rate in our experience may be due to the use of tubular retractors in ACF. The tube defines a working trajectory toward the neural foramen, which may help to reduce the risk of VA injury and excessive bone removal by facilitating bone trajectory orientation, thus minimizing the potential risks of iatrogenic instability.

When ACF is compared with ACDF and ADR, the clinical results are comparable; however, the total healthcare costs exceed those of foraminotomy procedures [9]. Furthermore, there was no reported significant difference in the reoperation rate between ACDF and foraminotomy [23].

Kim et al. [6] compared ACF and PCF in terms of clini$\mathrm{cal}$ and radiological results. They found that uncovertebral joint resection resulted in a significant decrease in disk height and loss of cervical lordosis during the first 6 months postoperatively after ACF with a stabilization of the radiological parameters thereafter and no difference in terms of clinical outcome at FU between ACF and PCF. Their reoperation rate was $0 \%$ for ACF patients and 5\% for PCF [6].

One study that compared ACF and ADR reported similar clinical results but different biomechanical outcomes. Range of motion was preserved for patients who underwent arthroplasty, whereas those who underwent foraminotomies exhibited reduced motion $[9,24]$. The conclusions of this study were limited by the small number of patients included; thus, a larger series with longer-term outcomes is required to compare ACF with ADR.

In our study, no clinical and radiological signs of instability were found at FU, and even when spontaneous fusion occurred after ACF, this remained asymptomatic in a single patient.

Kim et al. [6] have suggested PCF over ACF in patients with no disk degeneration, which seems unlikely considering the symptomatic nerve root compression; a clear advantage of ACF is that it preserves the facet joints compared with PCF with a less potential risk of instability [25]. The use of a tubular retractor technique in ACF may play a role in reducing the rate of instability at the operated level.

Compared with the recently described endoscopicassisted technique for ACF [26], tubular retractors have several advantages: the surgeon's familiarity with the microsurgical technique, the adequate working space in case of brisk bleeding, and the smooth learning curve.

The overall rate of complications for ACF in our series was low (4.4\%), which was comparable with other ACF and PCF series (Table 3) [5,8,11-13,15,16,21,22,24].

In this study, the neurological complications were two cases of Horner's syndrome, probably caused by excessive monopolar cautery over the longus colli muscle. Thus, we started to avoid monopolar cautery and switched to a blunt dissection of the prevertebral tissue with careful 
lateral mobilization of the loose fascia where the cervical sympathetic trunk runs $(10-15 \mathrm{~mm}$ lateral to the medial edge of the longus colli muscle). Despite the occurrence of Horner's syndrome, which was more frequent than reported in literature for ACDF [27], all patients experienced complete resolution of symptoms within 6 months to 1 year after surgery (Table 3) $[5,8,11-13,15,16,21,22,24]$.

Only two studies in the literature reported a complication rate of $>5 \%$ for ACF $[8,12]$. Saringer et al. [12] reported transient recurrent laryngeal nerve palsy, which occurred in $5.8 \%$ of patients operated for ACF through the left side with complete resolution of the palsy after 4 weeks. Hacker et al. [16] reported a poor result in 58\% of patients who underwent ACF with a $15 \%$ rate of complications and a 5\% rate of reoperation. In their report, Hacker and coworkers attributed the unfavorable outcome in their series to the steeper learning curve of anterior foraminotomy and the fact that at that time the surgical technique was recently described with a relative lack of knowledge as to how to improve the surgical procedure and to avoid complications [28].

In terms of reoperation rate at the index level, the overall reoperation rate in this study was comparable with that reported in the literature for ACDF and other ACF series $[5,8,11-13,15,16,21,22,29]$ whereas PCF was reported to have a higher reoperation rate than ACF $[6,30]$.

Although this study has limitations due to the retrospective nature of the series, high selection bias (the same surgeon operated all patients), and the lack of a control group, our results add to the available literature about ACF, and our study is the first series to exploit the use of tubular retractors for ACF.

Despite the lack of studies comparing ACF with ACDF, previous studies comparing ACDF with PCF have reported a significantly lower cost due to the lack of implants and a lesser need for imaging studies at FU [7]. These data can be extrapolated for ACF, supporting the costeffectiveness of this procedure for patients with unilateral cervical radiculopathy.

\section{Conclusions}

Our study confirms that ACF is a safe and effective alternative to ACDF, ADR, and PCF in carefully selected patients, with satisfactory overall clinical results. Furthermore, the use of tubular retractors in ACF helps to maintain a safe corridor during bone removal for ACF, mini- mizing soft tissue manipulation and avoiding unnecessary bone removal. Our results are encouraging and confirm the safety and effectiveness of ACF. Thus, in low-income contexts, with limited availability of spine implants, ACF may be considered as a viable alternative procedure to ACDF in carefully selected patients with unilateral cervical radiculopathy.

\section{Conflict of Interest}

No potential conflict of interest relevant to this article was reported.

\section{Author Contributions}

RM: design of the study, manuscript drafting and revision, data collection; GC: data collection and radiological assessment; VA: data collection and radiological assessment; SPW: statistical analysis; LB: critical revision of the manuscript; and JMD: design of the study and critical revision of the manuscript.

\section{References}

1. Nguyen J, Chu B, Kuo CC, Leasure JM, Ames C, Kondrashov D. Changes in foraminal area with anterior decompression versus keyhole foraminotomy in the cervical spine: a biomechanical investigation. J Neurosurg Spine 2017;27:620-6.

2. Zou S, Gao J, Xu B, Lu X, Han Y, Meng H. Anterior cervical discectomy and fusion (ACDF) versus cervical disc arthroplasty (CDA) for two contiguous levels cervical disc degenerative disease: a metaanalysis of randomized controlled trials. Eur Spine J 2017;26:985-97.

3. Wang QL, Tu ZM, Hu P, et al. Long-term results comparing cervical disc arthroplasty to anterior cervical discectomy and fusion: a systematic review and meta-analysis of randomized controlled trials. Orthop Surg 2020;12:16-30.

4. Jho HD. Microsurgical anterior cervical foraminotomy for radiculopathy: a new approach to cervical disc herniation. J Neurosurg 1996;84:155-60.

5. Jho HD, Kim WK, Kim MH. Anterior microforaminotomy for treatment of cervical radiculopathy: part 1: disc-preserving "functional cervical disc surgery". Neurosurgery 2002;51:S46-53. 
6. Kim SJ, Seo JS, Lee SH, Bae J. Comparison of anterior cervical foraminotomy and posterior cervical foraminotomy for treating single level unilateral cervical radiculopathy. Spine (Phila Pa 1976) 2019;44:133947.

7. Liu WJ, Hu L, Chou PH, Wang JW, Kan WS. Comparison of anterior cervical discectomy and fusion versus posterior cervical foraminotomy in the treatment of cervical radiculopathy: a systematic review. Orthop Surg 2016;8:425-31.

8. Park YK, Moon HJ, Kwon TH, Kim JH. Long-term outcomes following anterior foraminotomy for oneor two-level cervical radiculopathy. Eur Spine J 2013;22:1489-96.

9. Yi S, Lim JH, Choi KS, et al. Comparison of anterior cervical foraminotomy vs arthroplasty for unilateral cervical radiculopathy. Surg Neurol 2009;71:677-80.

10. Grigorian IuA, Stepanian MA, Onopchenko EV, Kadin LA, Khimochko EB, Lunina ES. Microsurgical anterior cervical foraminotomy in spondylogenous cervical radiculopathy. Zh Vopr Neirokhir Im N N Burdenko 2008:31-5.

11. Lee JY, Lohr M, Impekoven P, et al. Small keyhole transuncal foraminotomy for unilateral cervical radiculopathy. Acta Neurochir (Wien) 2006;148:951-8.

12. Saringer W, Nobauer I, Reddy M, Tschabitscher M, Horaczek A. Microsurgical anterior cervical foraminotomy (uncoforaminotomy) for unilateral radiculopathy: clinical results of a new technique. Acta Neurochir (Wien) 2002;144:685-94.

13. Koc RK, Menku A, Tucer B, Gocmez C, Akdemir H. Anterior cervical foraminotomy for unilateral spondylotic radiculopathy. Minim Invasive Neurosurg 2004;47:186-9.

14. Tascioglu AO, Attar A, Tascioglu B. Microsurgical anterior cervical foraminotomy (uncinatectomy) for cervical disc herniation: report of three cases. J Neurosurg 2001;94:121-5.

15. Johnson JP, Filler AG, McBride DQ, Batzdorf U. Anterior cervical foraminotomy for unilateral radicular disease. Spine (Phila Pa 1976) 2000;25:905-9.

16. Hacker RJ, Miller CG. Failed anterior cervical foraminotomy. J Neurosurg 2003;98:126-30.

17. Maduri R, Bobinski L, Duff JM. Minimally invasive anterior foraminotomy for cervical radiculopathy: how I do it. Acta Neurochir (Wien) 2020;162:679-83.

18. Macnab I. Negative disc exploration: an analysis of the causes of nerve-root involvement in sixty-eight patients. J Bone Joint Surg Am 1971;53:891-903.

19. White AA, Panjabi MM. Clinical biomechanics of the spine. 2nd ed. Philadelphia (PA): Lippincott Williams \& Wilkins; 1990.

20. Witiw CD, Smieliauskas F, O’Toole JE, Fehlings MG, Fessler RG. Comparison of anterior cervical discectomy and fusion to posterior cervical foraminotomy for cervical radiculopathy: utilization, costs, and adverse events 2003 to 2014. Neurosurgery 2019;84:413-20.

21. Umebayashi D, Hara M, Nakajima Y, Nishimura Y, Wakabayashi T. Transvertebral anterior cervical foraminotomy: midterm outcomes of clinical and radiological assessments including the finite element method. Eur Spine J 2013;22:2884-90.

22. Choi G, Lee SH, Bhanot A, Chae YS, Jung B, Lee S. Modified transcorporeal anterior cervical microforaminotomy for cervical radiculopathy: a technical note and early results. Eur Spine J 2007;16:1387-93.

23. Lubelski D, Healy AT, Silverstein MP, et al. Reoperation rates after anterior cervical discectomy and fusion versus posterior cervical foraminotomy: a propensitymatched analysis. Spine J 2015;15:1277-83.

24. Broekema AE, Kuijlen JM, Lesman-Leegte GA, et al. Study protocol for a randomised controlled multicentre study: the Foraminotomy ACDF CostEffectiveness Trial (FACET) in patients with cervical radiculopathy. BMJ Open 2017;7:e012829.

25. Cornelius JF, Bruneau M, George B. Microsurgical cervical nerve root decompression via an anterolateral approach: clinical outcome of patients treated for spondylotic radiculopathy. Neurosurgery 2007;61:972-80.

26. Saringer WF, Reddy B, Nobauer-Huhmann I, et al. Endoscopic anterior cervical foraminotomy for unilateral radiculopathy: anatomical morphometric analysis and preliminary clinical experience. J Neurosurg 2003;98:171-80.

27. Lubelski D, Pennington Z, Sciubba DM, Theodore $\mathrm{N}$, Bydon A. Horner syndrome after anterior cervical discectomy and fusion: case series and systematic review. World Neurosurg 2020;133:e68-75.

28. Jho HD. Failed anterior cervical foraminotomy. J Neurosurg 2003;98:121-5.

29. Mai HT, Chun DS, Schneider AD, Hecht AC, Maroon JC, Hsu WK. The difference in clinical outcomes after anterior cervical fusion, disk replacement, and fo- 
raminotomy in professional athletes. Clin Spine Surg 2018;31:E80-4.

30. MacDowall A, Heary RF, Holy M, Lindhagen L, Olerud C. Posterior foraminotomy versus anterior decompression and fusion in patients with cervical degenerative disc disease with radiculopathy: up to 5 years of outcome from the National Swedish Spine Register. J Neurosurg Spine 2020;32:344-52. 